\title{
A MEDIAÇÃO DE CONFLITOS NA EDUCAÇÃO NUMA PERSPECTIVA DIALÉTICA E A PRÁTICA DA ORIENTÁDORA EDUCACIONAL
}

\author{
LA MEDIACIÓN DE CONFLICTOS EN LA EDUCACIÓN EN UNA PERSPECTIVA \\ DIALÉTICA Y LA PRÁCTICA DE LA ORIENTADORA EDUCACIONAL
}

THE MEDIATION OF CONFLICTS IN EDUCATION IN A DIALECTIC PERSPECTIVE AND THE PRACTICE OF THE EDUCATIONAL ADVISOR

Adriana Janice LENZ1

Moacir Fernando VIEGAS ${ }^{2}$

RESUMO: O artigo apresenta revisão teórica que tem o propósito de refletir sobre a mediação de conflitos na prática da Orientação Educacional. Detém-se especialmente no significado da mediação, dando destaque à mediação dialética, perspectiva teórica que, acredita-se, oferece amplas possibilidades de desenvolvimento de habilidades e competências e de transformações nas práticas educativas das profissionais que atuam nesse campo. $\mathrm{O}$ texto se justifica pela pouquíssima disponibilidade de produções que abordem o tema, tanto no que se refere a artigos como dissertações e teses. A partir da longa experiência profissional de um dos autores do artigo, busca-se inicialmente analisar o significado dos conceitos de mediação e de conflito, destacando-se aspectos históricos e principais concepções, para em seguida discutir o papel da Orientadora Educacional na gestão e mediação de conflitos.

PALAVRAS-CHAVE: Orientação educacional. Mediação de conflitos. Prática educativa.

RESUMEN: El artículo presenta revisión teórica que tiene el propósito de reflexionar sobre la mediación de conflictos en la práctica de la Orientación Educacional. Se detiene especialmente en el significado de la mediación, dando destaque a la mediación dialéctica, perspectiva teórica que, se cree, ofrece amplias posibilidades de desarrollo de habilidades y competencias y de transformaciones en las prácticas educativas de los profesionales que actúan en este campo. La revisión teórica se justifica por la poquísima disponibilidad de producciones que aborden el tema, tanto en lo que se refiere a artículos como disertaciones y tesis. A partir de la larga experiencia de uno de los autores del artículo, se busca inicialmente analizar el significado de los conceptos de mediación y de conflicto, destacándose aspectos históricos y principales concepciones, para em seguida discutir el papel de ese profesional en la gestión y mediación de conflictos.

PALABRAS CLAVE: Orientación educacional. Mediación de conflitos. Práctica educativa.

\footnotetext{
${ }^{1}$ Escola Municipal de Ensino Fundamental Professor José Ferrugem, Venâncio Aires - RS - Brasil. Orientadora Educacional. Mestre em Educação. ORCID <http://orcid.org/0000-0002-9326-9070>. E-mail: adrianajlenz@yahoo.com.br

${ }^{2}$ Universidade de Santa Cruz do Sul (UNISC), Santa Cruz do Sul - RS - Brasil. Programa de Pós-Graduação em Educação. Doutor em Educação. ORCID <http://orcid.org/0000-0003-0261-1334>. E-mail: moacirfviegas@gmail.com

RPGE- Revista on line de Política e Gestão Educacional, Araraquara, v. 23, n. 3, 561-575, set./dez., 2019. E-ISSN: 1519-9029 DOI: $10.22633 /$ rpge.v23i3.12483 (cc) BY-NC-SA 
ABSTRACT: The article presents a theoretical review that has the purpose of reflecting on the mediation of conflicts at the practice of Educational Orientation. The main focus is on the meaning of the mediation, highlighting the dialectic mediation, theoretical perspective that, as we believe, offer broad possibilities of developing the skills and social abilities and also transformations on the educative practices of the professionals that work on this field. The theoretical review is justified by the extremely small availability of productions that approaches the subject, both regarding articles as well as dissertations and theses. From the long experience of one of the article's authors, we initially seek to analyze the meaning of the concepts of mediation and conflict, highlighting historical aspects and main conceptions, to then discuss the role of these professionals on the management and mediation of conflicts.

KEYWORDS: Educational orientation. Mediation of conflicts. Educative practice.

\section{Introdução}

$\mathrm{O}$ interesse pelo tema desse artigo tem origem no percurso como orientadora educacional de um de seus autores ao longo de 24 anos, percurso no qual as dúvidas e incertezas sobre a atuação profissional são uma constante. Parte dessas incertezas decorre do pouco conhecimento teórico que, em geral, as orientadoras têm a respeito de sua prática, sendo muito comum as queixas quanto à falta de materiais específicos sobre seu trabalho.

Tais reclamações correspondem ao que encontramos em nossa revisão do Banco de Teses e Dissertações e no Portal de Periódicos da Capes, onde é nítida a fraca produção específica no campo da Orientação Educacional. Contrastando com a crescente importância do trabalho desempenhado pelas profissionais ${ }^{3}$ dessas práticas educativas, as quais têm se convertido no principal sujeito da gestão da mediação de conflitos nas relações entre alunos, pais e professores, o número de pesquisas e publicações é muito pouco expressivo. Em termos de teses e dissertações, considerando todas as áreas de conhecimento, foram produzidas, no total, 67 trabalhos entre os anos 1988 e 2018, sendo apenas 17 nos últimos dez anos. E apenas uma indica como tema principal de estudo, em seu enunciado, a prática da orientadora educacional na mediação de conflitos.

Já a busca no Catálogo de Periódicos da Capes e no SciELO pelos termos “orientação educacional" e "orientador educacional" revelou a existência de apenas nove artigos que

\footnotetext{
${ }^{3}$ A grande maioria das profissionais que atuam na Orientação Educacional é formada por mulheres. Desse modo,
} optamos pelo tratamento no gênero feminino. 
possuem como foco central a prática da orientadora educacional, incluindo trabalhos teóricos e empíricos.

Diante desse quadro, esse artigo tem o propósito de contribuir para o fomento da discussão teórica da prática das orientadoras educacionais. Nossa atenção se detém especialmente nas características da mediação, atividade que melhor define, na atualidade, a prática dessas profissionais, dando destaque à mediação dialética, perspectiva teórica que oferece amplas possibilidades de desenvolvimento de habilidades e competências sociais e de transformações na realidade escolar.

O artigo se justifica também pela necessidade de ampliação do debate sobre o tema da mediação de conflitos, que, ao envolver trabalhadores, crianças e jovens, pode contribuir com os processos de democratização das relações sociais.

Iniciamos o artigo trazendo o conceito de mediação, para em seguida abordarmos brevemente, dadas as dimensões desse artigo, o conceito de conflito. No terceiro tópico o foco é mediação de conflitos na perspectiva dialética. Por fim, discutimos a prática da orientadora educacional na mediação de conflitos na escola.

\section{Mediação: aspectos históricos e conceituais}

Começamos por definir a palavra mediação a partir da origem do termo, que vem do latim mediatio ou meditationis, que significa "intervenção com que se busca produzir um acordo" e também "processo pacífico de acerto de conflitos" (SALES, 2009, p. 23). No Dicionário Básico de Filosofia (JAPIASSÚ; MARCONDES, 2000, p. 127), os autores afirmam que "na tradição filosófica clássica, a noção de mediação liga-se ao problema da necessidade de explicar a relação entre duas coisas, sobretudo entre duas naturezas distintas". Desse modo, eles trazem a ideia de intermediação, como ponte de passagem de uma coisa à outra.

Para Signates (1998), o conceito de mediação tem origem nas duas principais correntes filosóficas: a idealista, de origem cristã, e a dialética, originária de Hegel e Marx. Na filosofia idealista, o termo já se estabelecera como conciliação entre opostos dentro de uma totalidade. Ou, num sentido mais "neutro", interação entre forças separadas. Ou, ainda, conexão indireta, uma agência, entre tipos separados de ato. Já a dialética materialista, incluindo a teoria crítica, teoriza a mediação fundamental que permite pensar a relação entre a transformação na produção econômica e as mudanças no espaço da cultura, onde a contradição desempenha papel fundamental, por desempenhar a função de "motor" do desenvolvimento dos fenômenos. 
Segundo o mesmo autor (SIGNATES, 1998), o significado mais corrente de mediação vincula-se à ideia do intermediário, ou seja, àquele que se liga ao primeiro, ou dele deriva, por intermédio do segundo. Mas, para ele, a mediação não se reduz à intermediação.

Queremos destacar, principalmente, a mediação como categoria filosófica, que, de acordo com Oliveira, Almeida e Arnoni (2007, p. 101), "atinge seu pleno desenvolvimento em Hegel", de onde se origina o seu caráter dialético, que a impede de ser considerada como produto. Como processo, funda-se na tensão e no movimento.

Para Cury, a categoria da mediação se justifica quando o real não é visto numa divisibilidade em que cada elemento guarde em si mesmo o dinamismo de sua existência, e sim quando é entendido como um processo recíproco em que os contrários se relacionem de modo dialético e contraditório. Nas suas palavras, "sob o ponto de vista da sociedade, as mediações concretizam e encarnam as ideias ao mesmo tempo em que iluminam e significam as ações" (CURY, 2000, p. 27).

Assim, conforme o autor, o conceito de mediação indica que nada é isolado, implicando uma conexão dialética entre tudo o que existe. A mediação, como parte inerente às relações sociais entre pensamentos e práticas, guarda estreita relação com a categoria de ação recíproca, na medida em que aquela não atua apenas como reprodutora das ideologias que dominam em uma determinada época, podendo constituir-se como mediação crítica, contribuindo para combater, por meio das contradições sociais, as explicações superficiais que as ideologias dominantes tentam impor.

Historicamente, os primeiros registros do uso da mediação como prática social remontam a Grécia Antiga (MOORE, 1998). Crimes e questões de guerra costumavam ser levados à corte, onde as pequenas causas eram objetos de mediação. As culturas judaicas, cristãs, hinduístas, islâmicas, budistas, confucionistas e também algumas indígenas possuem longa tradição na prática da mediação e as comunidades judaicas a utilizavam para solucionar disputas religiosas e civis. Durante séculos, a igreja católica e a ortodoxa foram as principais mediadoras de litígios. Era o clero quem mediava disputas familiares, criminais e diplomáticas. De acordo com Moore (1998, p. 32),

As tradições judaicas de solução de conflitos foram transportadas para as comunidades cristãs emergentes, que viam Cristo como mediador supremo. A Bíblia se refere a Jesus como mediador entre Deus e o homem. [...] Este conceito de intermediário foi finalmente adotado para definir o papel do clero como mediador entre a congregação e Deus e entre os crentes 
Segundo o mesmo autor, entre as culturas islâmicas, desde as sociedades pastoris, os conflitos entre as tribos eram resolvidos por meio de reuniões com a comunidade dos idosos, que então eram os sujeitos mediadores. Já as aldeias hindus da Índia empregam tradicionalmente o sistema de justiça panchayat, em que um grupo de cinco membros tanto medeia quanto arbitra as disputas e queixas dentro da comunidade (MOORE, 1998).

Nota-se assim, que a formação dos mediadores de outras épocas e culturas, assim como a própria prática de mediação, caracterizavam-se como um processo informal, oriundo da experiência, a mediação sendo desenvolvida de forma assistemática em meio a outras funções ou deveres. Ela vai adquirir um caráter institucionalizado e profissional somente no século XX, vindo a expandir-se mundialmente, com maior intensidade, no último quarto desse século. Para Moore,

Este crescimento deve-se em parte a um reconhecimento mais amplo dos direitos humanos e da dignidade dos indivíduos, à expansão das aspirações pela participação democrática em todos os níveis sociais e políticos, à crença de que um indivíduo tem o direito de participar e de ter o controle das decisões que afetam a sua própria vida, a um apoio ético aos acordos particulares e às tendências, em algumas regiões, para maior tolerância a diversidade (MOORE, 1998, p. 34).

Em nossa história recente, o uso da mediação ampliou-se primeiro nos Estados Unidos e no Canadá, sendo o terreno das relações trabalhistas o espaço social onde foi iniciada como prática institucionalizada. Segundo Moore (1998), isto está relacionado ao objetivo de promover estabilidade e acordos entre patrões e empregados por meio da negociação coletiva. Esperava-se que os acordos mediados pudessem evitar greves e paralisações consideradas dispendiosas e que melhorassem a segurança, o bem-estar e a prosperidade dos americanos. Podemos considerar que, nesse caso, a mediação por organizações institucionalizadas, como os sindicatos, substituiu a organização operária nos locais de trabalho, onde as negociações e enfrentamentos se davam diretamente entre empregados e patrões, gerando maiores níveis de conflito.

A partir daí a mediação se expandiu para as mais diversas atividades sociais, como as disputas étnicas, econômicas, comerciais, jurídicas ou em questões mais específicas, como as relacionadas aos imigrantes, desabrigados, ao trabalho policial, ao meio ambiente etc.

Na América Latina, nos anos 1990, a Colômbia foi a pioneira em iniciar o processo de mediação em suas práticas legais, o que acabou influenciando os países vizinhos, como o Peru. Mas, em que pese o desenvolvimento da atividade de mediação em realidades e práticas sociais cada vez mais amplas e distintas, apenas muito recentemente passou-se a se preocupar com 
"estudos sistemáticos ou descrições das estratégias e táticas específicas utilizadas" (MOORE, 1998, p. 27), dando origem assim a um saber sistematizado a seu respeito.

\section{Breves considerações sobre o conflito}

Dado que nossa preocupação central ao abordarmos a prática da mediação relaciona-se à mediação de conflitos na realidade escolar, é importante trazermos, mesmo que brevemente, algumas considerações sobre o conflito.

A palavra "conflito" tem origem no latim conflictu, que significa choque, combate ou luta. Em sua etimologia está presente a ideia de duas partes em oposição. No Dicionário de Política, o conflito é definido como "uma forma de interação entre indivíduos, grupos, organizações e coletividades que implica choques para o acesso à distribuição de bens escassos" (BOBBIO; MATTEUCCI; PASQUINI, 1992, p. 225). E Tzu (2000, p. 32), numa definição muito interessante, afirma que o conflito "é luz e sombra, perigo e oportunidade, estabilidade e mudança, fortaleza e debilidade".

Ao longo de nossa história, a medida em que, no ocidente, as sociedades rigidamente hierarquizadas foram dando lugar a relações sociais mais complexas e horizontais, a formação de consensos entre diferentes pontos de vista passou a ocupar a atenção de intelectuais. Durkheim (1999), um dos que mais influenciaram na concepção positivista ainda muito forte até os fias de hoje, tratou o conflito como uma patologia que deveria ser extinta do sistema social. Na teoria durkheimiana encontramos a valorização do coletivo em detrimento do individual, do consenso em detrimento do dissenso.

As ideias de Durkheim são bastante questionáveis, na medida em que sua concepção de consenso é acompanhada da necessidade de acomodação dos sujeitos ao equilíbrio do coletivo, de sua conformação unilateral à ordem social, o que significa manter as coisas tais como se apresentam, ignorando as contradições sociais e as necessidades de transformações mais profundas.

Já Max Weber (1992) via o conflito como processo social típico de todas as sociedades únicas, enquanto Simmel (1983) entendia-o como “inerente às múltiplas interações de uns-comos-outros, contra-os-outros e pelos-outros" que constituem o viver em sociedade (SIMMEL, 1983, p. 125).

A nosso ver, os conflitos são uma característica essencial dos grupos sociais que constituem a sociedade e se configuram como parte fundamental do desenvolvimento e 
crescimento de qualquer sistema familiar, social, político e organizacional. Para Fernandes (1993, p. 787), "as sociedades vivem em estado de permanente conflitualidade", não existindo vida social sem antagonismos.

Entendemos que em sua tarefa de desenvolver o ensino e a aprendizagem, a escola está implicada, juntamente com a comunidade escolar, na gestão dos conflitos que fazem parte do seu cotidiano. A escola é uma instituição em que se processam mediações. A construção de uma sociedade melhor depende de uma autoridade construída pela capacidade de diálogo e pela gestão de conflitos que reconheça a dimensão política das práticas educativas, o que demanda dos profissionais que atuam na escola o exercício da autoridade com justiça e a abertura para o diálogo, onde os conflitos sejam mediados visando à emancipação e a autonomia dos sujeitos.

Para Burguet (2005, p. 42), "os alunos necessitam entender os conflitos, aprender formas alternativas para resolvê-los e buscar soluções que sejam satisfatórias para todos". Conflitos constituem oportunidades de aprendizado para toda a comunidade escolar. As salas de aula livres de desavenças é que são incomuns. Desta maneira, a mediação pedagógica e dialética de conflitos pode fortalecer a escola como um espaço formador de sujeitos políticos e críticos, que exercitam o diálogo nas situações de crise e promovem a mediação entre as partes.

\section{A mediação de conflitos na educação numa perspectiva dialética}

Como campo de pesquisa, a mediação surgiu no Brasil no final da década de 1980 nas áreas da sociologia, do direito e da psicologia, chegando também na educação e na realidade escolar. Para Oliveira, Almeida e Arnoni (2007, p. 76), a mediação "é uma categoria fundamental quando se trata das atividades educativas". Porém, predomina entre os educadores uma visão em que eles se percebem como mediadores apenas das situações de aprendizagem dos conteúdos escolares nas situações de sala de aula, reservando-se exclusivamente às orientadoras educacionais o papel de mediação dos conflitos.

Na visão de Sforni (2003), em que pese a importância da mediação nas construções cognitivas dos alunos, ela não pode ser reduzida a essa prática, devendo ser ampliada para as relações sociais. A autora propõe, então, ampliar o conceito incluindo a mediação social, entendida como "ação compartilhada entre pessoas com os elementos mediadores" (SFORNI, 2003, p. 5).

Para Cury (2000), a mediação desempenha um papel crucial na educação. Como organizadora e transmissora de ideias, a educação funciona como mediadora das ações da 
prática social e das ideias, contribuindo, por meio do movimento produzido nas interações entre elas, para gerar novas práticas e ideias, de qualidade superior. Conforme o autor, esse movimento "permite entender como, sem essa categoria, a educação acaba formando um universo à parte, existente independentemente da ação. Esta categoria [a mediação] permite superar o aparente fosso existente entre as ideias e a ação" (CURY, 2000, p. 28).

Conforme ainda o autor, as mediações estão relacionadas à produção de ideologias sociais, que tanto podem ser reprodutoras do status quo como transformadoras. Assim, a educação como mediação "tanto funciona para a afloração da consciência, como para impedila, tanto para difundir, como para desarticular" (CURY, 2000, p. 66). Desse modo, a educação tem o potencial de ajudar a elaborar a forma de pensar que, convertida em mediadora, pode tornar-se valioso instrumento de apoio na transformação social.

Isso significa que a educação, enquanto mediação, possui um caráter político intrínseco e contraditório:

Ao nível do político ela prepara as gerações segundo os padrões axiológicos estabelecidos, tenta legitimá-los e torná-los senso comum. Mas a educação política é em si mesma contraditória porque carrega consigo a função de reduzir os conflitos nascidos das relações sociais, vinculando-os a uma visão de mundo dissimuladora dos mesmos e desorganizadora da concepção de mundo que se lhe impõe (CURY, 2000, p. 68)

Analisando esta definição, remetemo-nos as origens da Orientação Educacional, quando a compreensão dominante era que os alunos deveriam ser meramente adaptados ao processo de ensino. A tarefa dos especialistas era trabalhar com os alunos mais revoltados, acalmar os ânimos e abafar com "panos quentes" os tumultos na escola. Com esta prática, as orientadoras contribuíam e ainda contribuem para a manutenção do status quo.

O uso do vocábulo mediação tem sido frequente entre os investigadores do campo da educação, tanto no Brasil quanto na América Latina, o que, segundo Oliveira, Almeida e Arnoni (2007), é acompanhado pela imprecisão dos sentidos que ele assume. Para os autores, costumase falar "no papel do professor como mediador da relação entre o ensino e a aprendizagem, ou do caráter mediador presente na ligação que se estabelece entre o conhecimento sistematizado pelas ciências e aquele que o aluno desenvolve no seu cotidiano" (OLIVEIRA; ALMEIDA; ARNONI, 2007, p. 100). Nessa concepção, segundo eles, à mediação é atribuído o papel de eliminação ou minimização da "diferença entre os termos ensino e aprendizagem, conhecimento sistemático e experiência cotidiana e entre o professor e seus alunos" e, nesse 
sentido, seu significado tem a ver com união, unificação, igualdade e, principalmente, de resultado.

Nessa forma de entendimento, a mediação funciona como homogeneizadora de dois elementos opostos, ou seja, como um resultado, um produto, e não um processo. Para os mesmos autores, quando se compreende a mediação como um produto, concepção amplamente difundida no campo da educação, a necessária relação entre dois termos se reduz à soma de ambos, o que resulta na sua anulação mútua.

$\mathrm{Na}$ dialética, pelo contrário, a mediação é entendida como processo e como possibilidade de transformação das consciências e das práticas pedagógicas. Ao invés de uma relação em que se busca um acordo, no sentido de homogeneização dos termos, na dialética a mediação significa uma relação de tensão entre termos diferentes: o imediato e o mediato. É por meio da mediação que ocorre a superação do imediato, transformado em mediato (OLIVEIRA; ALMEIDA; ARNONI, 2007)

A mediação é, portanto, uma força negativa que une o imediato ao mediato e, por isso, também os separa e os distingue. Entendem os autores que, mesmo permitindo a passagem de um termo a outro, ela não é apenas uma "ponte" entre os dois polos, mas também "um dos elementos da relação responsáveis por viabilizá-la” (OLIVEIRA; ALMEIDA; ARNONI, 2007, p. 102). Não anulando os dois termos, ela permite que o imediato se faça presente no mediato, constituindo uma relação de reciprocidade entre os dois termos.

A ideia norteadora da mediação pedagógica dialética é de que o processo educativo é constituído de mediações, portanto não pode haver educação sem que haja mediação. E, segundo os autores, se há mediação, há necessariamente dois termos opostos e não-antagônicos, um que está no plano imediato e outro no mediato. E na prática educativa, “quem está no plano imediato é o aluno e quem está ou deveria estar no plano mediato é o professor" (OLIVEIRA; ALMEIDA; ARNONI, 2007). Afirmando ainda que o imediato não é mais pobre nem inferior ao mediato, e sim distinto e oposto, os autores concluem que, portanto, não existe nem hierarquia nem dominação ou subordinação na relação entre eles.

De fundamental importância para a prática educativa é a compreensão de que a mediação não é espontânea ou automática, devendo haver um esforço para que ela aconteça. No dia a dia estamos mergulhados na imediatez que caracteriza o cotidiano, o que não é diferente com relação aos estudantes. A prática educativa é que possibilita sair desse plano imediato. Assim, é de responsabilidade do professor a ação que leva a superação do "plano imediato no do mediato", possibilitando que os alunos "tenham acesso ao conhecimento 
produzido, historicamente, pela humanidade" (OLIVEIRA; ALMEIDA; ARNONI, 2007, p. 108-109).

Quando transpomos essas ideias para o plano dos conflitos escolares, percebemos que por meio do processo de ensino-aprendizagem é possível percebê-los como uma oportunidade de diálogo e de crescimento. A ação da orientadora educacional pode proporcionar que o aluno saia do imediato em que se encontra em uma situação de conflito, para o mediato, um nível superior de entendimento que lhe possibilita uma prática diferente daquela que gerou o conflito.

\section{A prática da orientadora educacional na mediação de conflitos}

Em nossa experiência no diálogo com as orientadoras educacionais, percebemos que frequentemente são trazidas falas da prática limitadas pela falta de uma teoria consistente, que permita um planejamento e uma ação com objetivos definidos. Mesmo que pese a importância da experiência que construímos ao longo de nossas trajetórias profissionais, ela muitas vezes não é suficiente para ultrapassar o senso comum, para ir além da sensação de repetição do mesmo que inevitavelmente nos apossa quando estamos afastados por muito tempo de uma reflexão apoiada em teorias, as quais acessamos, por exemplo, em cursos de aperfeiçoamento, especialização ou mesmo em capacitações. E como assinalamos acima, os indicativos são de que há poucos recursos teóricos e cursos específicos para o campo da Orientação Educacional.

Pressionados constantemente a dar respostas imediatas às demandas crescentes, educadores e orientadoras educacionais agem muitas vezes pelas impressões que têm do que é certo e errado, apoiando suas ações apenas na experiência que têm do dia-a-dia, o que, como dissemos, é importante, mas não suficiente. Para Triviños,

[...] no viver cotidiano, o ser humano, em geral, para interpretar, descrever, compreender e explicar os fenômenos materiais, não precisa buscar ou conhecer a essência dos fenômenos materiais. Basta apoiar-se em suas percepções que são fruto de sua experiência (TRIVIÑOS, 2006, p. 122).

Mas, para o autor, é necessário que conheçamos as bases teóricas que sustentam as práticas sociais. Sem o conhecimento dessas bases, o entendimento da própria prática fica comprometido, e da mesma forma o desenvolvimento de melhores práticas.

Conforme Enguita (2004), para entender o que se passa na escola não basta olhar para o aluno e sua origem social e cultural, sendo necessário também perceber as relações que articulam a escola, tanto no seu interior como no exterior. A alternativa proposta por ele para 
compreender essas relações na perspectiva do conflito, que considera como a mais adequada, é reconhecer e analisar os conflitos e contradições que atravessam o espaço social global, o cenário escolar e a articulação entre ambos. Segundo o autor,

Esse reconhecimento deve servir para uma análise que estará predominantemente centrada na dinâmica reprodutiva da escola, na sua contribuição com a reprodução da sociedade: se trata da reprodução de uma sociedade contraditória, por uma instituição contraditória em uma relação contraditória (ENGUITA, 2001, p. 27).

Na sociedade contemporânea, as rápidas transformações que afetam a escola ampliaram os desafios na busca da democracia, da inclusão social, dando à mediação de conflitos uma função essencial. Frente às demandas e expectativas da comunidade escolar, a orientadora tem se configurado no principal sujeito mediador nas inúmeras situações de conflito instauradas no dia a dia, as quais envolvem alunos, professores e pais. Dada a necessidade de resposta rápida e imediata, é comum a queixa das orientadoras educacionais de que ficam reduzidas a "bombeiros", "apagando o fogo" sempre que um conflito se instaura. E então, preparadas ou não, precisam mediar os conflitos que aparecem.

É preciso reconhecer que as orientadoras educacionais chegaram a transformar-se naquilo que se esperava delas nas últimas décadas, desde o surgimento da profissão nos tempos de ditadura militar, ou seja, em consensualizadoras, disciplinadoras ou ajustadoras dos comportamentos rebeldes e contrários à ordem. Como afirmava Gadotti no início desse milênio, referindo-se aos especialistas da educação, "o pedagogo se tornou mais um policial da educação do que um homem formado para criar a educação" (2003, p. 55, grifo do autor). Isso explica, em parte, o conflito de identidade que hoje vivem as profissionais da orientação, na medida em que, apesar nos ventos da democracia, sobrevivem na realidade escolar as condições sociais que sustentam uma perspectiva autoritária de sua prática, ao mesmo tempo em que se demanda, de forma crescente, uma atuação crítica que supere essa concepção.

Aceitar as demandas escolares tais como se apresentam significa, para as orientadoras, assujeitar-se a uma posição de espera, perpetuando a concepção tradicional. Para Azevedo e Garcia (1984, p. 35), quando a orientadora educacional estimula o pensamento convergente e o consenso a partir de "verdades absolutas e imutáveis", impede às classes subalternas de desenvolverem uma visão crítica, de pensamento divergente, de busca de novas verdades que lhes possibilitem reescrever sua história.

Segundo as mesmas autoras, cada enfoque curricular pressupõe uma concepção de mundo e de homem. Se a visão da orientadora é fechada na ideia de que os homens se 
distinguem pelas suas aptidões e esforços individuais, sendo isso o que determina a distância que percorrem até os fins pretendidos, a ação se dará num sentido. Mas, se a visão de homem é aberta e dialética, onde ele é considerado como ontologicamente igual, no entanto desigual pelas oportunidades desiguais que a sociedade de classes lhe determina, então a prática profissional se encaminha em outro sentido.

A orientação educacional exerce um importante papel na mediação de conflitos no sentido de que estes possam ser geridos de forma positiva, sendo percebidos como uma oportunidade de crescimento para os indivíduos envolvidos e para o grupo social em que estão inseridos. Muitos problemas da escola podem ser resolvidos de maneira melhor quando, por exemplo, os alunos são ouvidos e convidados a participar da construção de normas. Eles percebem o que está em jogo, ficam "ligados" se há uma escuta atenta e qualificada e se encontram a possibilidade de estabelecer um diálogo saudável.

Em sua prática profissional, as orientadoras educacionais podem propiciar os elementos necessários à compreensão do conflito não disponibilizados em outras relações sociais vivenciadas pelos estudantes. Por meio da reflexão construída nos espaços escolares, o exercício da mediação constitui-se em oportunidades de crescimento pessoal, de consciência de si e de reconhecimento do outro. Como prática educativa, promove a mudança de postura diante de outras situações de conflito enfrentadas pelos sujeitos, contribuindo para a diminuição da violência onde quer que ela se manifeste. Porém, o que temos percebido é que uma orientação educacional que aproveite todas as possibilidades da mediação ainda é pouco desenvolvida nas escolas.

Pensamos que uma compreensão crítica de mundo depende de mediações e por quantos mais processos de mediação passar o sujeito, mais conhecerá a sua condição social. Porém, quanto menos, mais vulnerável se tornará. Os processos de mediação pelos quais passa o sujeito lhe oferecem a possibilidade de reflexão acerca de sua situação social frente aos mecanismos sociais opressores, trazendo-lhe novas possibilidades para sua ação.

\section{Considerações Finais}

Os profissionais da educação enfrentam todos os dias uma realidade escolar que parece, muitas vezes, ter transformado a escola em um local pouco fraterno. Vemos como a mídia apresenta frequentemente situações, envolvendo alunos, professores e comunidade escolar, nas quais a violência se faz cada vez mais presente. Frente a essa realidade, propor ações que 
incentivem a mediação dos conflitos de forma crítica, dinâmica e responsável, nos parece ser uma forma de enfrentar essas situações.

A escola é um espaço socializador por natureza, onde amigos se encontram, onde as relações se tecem, onde se aprende a conviver com o outro. Tornar esse espaço agradável é um desafio para professores, gestores e alunos. Muitos fatores estão contribuindo para que isso não aconteça, como a ausência de diálogo, a falta de solidariedade e a intolerância com as diferenças.

Dado que a violência é, por definição, a negação da palavra e do diálogo, para seguirmos em frente talvez seja necessário pensar estratégias de abertura a uma função educativa integradora, democrática e de acesso à mediação de conflitos como uma cultura do universo escolar. Pedir aos estudantes tolerância e respeito às diferenças sem provê-los das habilidades necessárias, é algo, para nós, sem sentido. Não há como esperar de estudantes tais atitudes se a cultura em que vivem lhes solicita e instiga o contrário. A escola é um lugar ideal para a prática e os valores da mediação e este é um trabalho que a educação pode fazer pelas gerações atuais e futuras.

Acreditamos que é preciso trabalhar com o aluno na perspectiva da totalidade das mediações em que está envolvido em sua prática social, desenvolvendo o sentido da singularidade, da autonomia e da solidariedade. Nesse sentido, a mediação dialética pode construir novas formas de diálogo e de relacionamento interpessoal, pois se baseia nas negociações pelo bem comum. A escola pode encontrar na mediação um instrumento para lidar com o conflito de modo positivo, como oportunidade de crescimento, construindo sobre esta base uma forma de aprendizagem para toda a sociedade e para toda a vida.

Em nossa experiência profissional, ficamos felizes em perceber nas falas de muitas orientadoras que cada vez mais o poder da palavra é oferecido ao educando. Nossa intenção aqui foi justamente refletir sobre esta forma de ação como possibilidade de construção de um processo de mediação dialética. Este é o caminho que entendemos deve perseguir a mediação: por meio da escuta e do diálogo, sair da aparência, do plano imediato, para o não dito do plano mediato. Como diz Kosik (1976, p. 224, grifos do autor), "só a dialética do próprio movimento das coisas transforma o futuro, desvaloriza o futuro imediato como falsidade ou unilateralidade e reivindica como verdade o futuro mediato".

Acreditamos que um ambiente escolar mediador pode propiciar espaços para que os sujeitos aprendam a administrar conflitos. Quando os sujeitos desenvolvem as capacidades de dialogar e de escutar, se qualificam como agentes de mudança e de transformação. É na 
experiência do diálogo que formamos nossa cultura, nossos valores e objetivos, em que podemos nos educar para a paz e para uma boa convivência. E nas práticas educativas que irão proporcionar as habilidades e os espaços para que isso ocorra ocupam papel fundamental as orientadoras educacionais.

\section{REFERÊNCIAS}

AZEVEDO, Joanir Gomes de; GARCIA, Regina Leite. A orientação educacional e o currículo. Cadernos de Pesquisa, n. 48, p. 29-37, 1984.

BOBBIO, Norberto; MATTEUCCI, Nicola; PASQUINO, Gianfranco. Conflito. In:

Dicionário de política. 4. ed. Brasília: EDUnB, p. 225-230, 1992.

BURGUET, Marta. Diante do conflito... uma aposta na educação. In: VINYAMATA, Eduard (Org.). Aprender a partir do conflito: conflitologia e educação. São Paulo: Artmed, p. 4149, 2005.

CURY, Carlos Roberto Jamil. Educação e contradição: elementos metodológicos para uma teoria crítica do fenômeno educativo. 7. ed. São Paulo: Cortez, 2000.

DURKHEIM, Émile. Método para determinar essa função. In: Da divisão do trabalho social. 2. ed. São Paulo: Martins Fontes, p. 32-37, 1999.

ENGUITA, Mariano Fernández. Educar em tempos incertos. Porto Alegre: Artmed, 2004.

FERNANDES, António Teixeira. Análise Social. Vol. XXVIII, p. 787-828, 1993. Disponível em: http://analisesocial.ics.ul.pt/documentos/1223292608S8kUR1qx0Wa77QV4.pdf. Acesso em: 13 maio 2018.

GADOTTI, Moacir. Educação e poder: introdução à pedagogia do conflito. 13. Ed. São Paulo: Cortez, 2003.

JAPIASSÚ, Hilton; MARCONDES, Danilo. Mediação. In: Dicionário básico de filosofia. 3 . Ed. Rio de Janeiro, p. 127-127, 2001.

KOSIK, Karel. Dialética do concreto. Rio de Janeiro: Paz e Terra, 1976.

MOORE, Christopher W. O processo de mediação: estratégias práticas para a resolução de conflitos. 2. Ed. Porto Alegre: Artmed, 1998.

NAZARETH, Eliana Riberti. Mediação: o conflito e a solução. São Paulo: Arte Paubrasil, 2009.

OLVEIRA, Edson Moreira de; ALMEIDA, José Luís Vieira de; ARNONI, Maria Eliza Brefere. Mediação dialética na educação escolar: teoria e prática. São Paulo: Ed. Loyola, 2007. 
SALES, Lília Maia de Morais. Mediação de conflitos: família, escola e comunidade. Florianópolis: Conceito Editorial, 2007.

SFORNI, Marta Sueli de Faria. Aprendizagem e desenvolvimento: o papel da mediação. Araraquara: Junqueira \& Marin, 2003.

SIGNATES, Luiz. Estudo sobre o conceito de mediação. São Paulo: ECA/USP. Novos olhares, v. 2, n. 2, p. 37- 49, 1998.

SIMMEL, Georg. A natureza sociológica do conflito: conflito e estrutura do grupo. In: MORAES FILHO, Evaristo (Org.). Simmel. São Paulo: Ática, p. 122-134, 1983.

TRIVIÑOS, Augusto Nibaldo Silva. A dialética materialista e a prática social. Movimento, v. 12, n. 2, p. 121-142, 2006.

TZU, Sun. A Arte da guerra. Porto Alegre: L\&PM, 2000.

WEBER, Max. Conceitos sociológicos fundamentais: metodologia das ciências sociais. Campinas: Cortez/Unicamp, 1992.

\section{Como referenciar esse artigo:}

LENZ, Adriana Janice; VIEGAS, Moacir Fernando. A mediação de conflitos na educação numa perspectiva dialética e a prática da orientadora educacional. Revista on line de Política e Gestão Educacional, Araraquara, v. 23, n. 3, 561-575, set./dez., 2019. E-ISSN: 1519-9029. DOI: $10.22633 /$ rpge.v23i3.12483

Submetido em: 25/04/2019

Revisões requeridas: 03/06/2019

Aprovado em: 31/07/2019

Publicado em: 15/08/2019 